\title{
Docencia en Neurocirugía
}

Desde tiempos antiguos, la docencia en medicina ha sido una necesidad y un desafío. Inicialmente era transmisión verbal de maestro a discípulo, de conocimientos basados en la observación y experiencia con poca evidencia científica. No había una forma estandarizada y estudiada de enseñar o aprender.

Actualmente, tanto la docencia de pregrado como de posgrado ha sido objeto de investigación, desarrollándose varios modelos de enseñanza que generalmente coinciden en el logro de habilidades y competencias. Dichas competencias están enmarcadas en roles fundamentales que debe cumplir un buen médico: experto, comunicador, líder, colaborador, académico, profesional y promotor de la salud.

Para lograr la destreza en dichas competencias, existen múltiples métodos de enseñanza (clases magistrales, debates, ensayos ficticios, modelaje, etc). También la tecnología ha influido en la docencia con acceso a bibliotecas instantáneas virtuales, fotos y videos de obtención inmediata, visualización 3D intraoperatoria de visión microscópica en tiempo real, webinars, modelos de simulación virtual de anatomía y planificación quirúrgica, práctica en simuladores con diseño en impresión 3D con o sin ayuda de neuronavegación.

Por otra parte, las generaciones actuales de alumnos son distintas a las previas. El uso intenso masivo de redes sociales, el acceso inmediato a la información, la búsqueda del resultado y de la recompensa inmediata con el mínimo esfuerzo posible, la noción de tener más derechos que deberes (reforzado por recomendaciones, por cierto saludables, como restricción horaria para residentes), entre otros, hacen que el residente de neurocirugía actual sea más exigente, eventualmente más eficiente y probablemente más sano al tener una mayor vida social y tiempo recreacional, comparados con los residentes más antiguos. Esto también puede asociarse a algunas desventajas como menor tolerancia a la frustración, menos resiliencia, menor priorización de neurocirugía como lo primordial, probable menor compromiso institucional y mayor conformismo con los logros básicos obtenidos, que se traduce por ejemplo en búsqueda de subespecialización con menos frecuencia o por períodos más cortos. Por lo tanto, los alumnos actuales también imponen un desafío adicional y requieren a mi juicio un sistema de enseñanza individualizado. Una amenaza que debe también ser considerada y que puede presentarse tanto en el mentor como en el alumno de cualquier especialidad, pero en especial en la neurocirugía es el síndrome de Hubris (descrito recientemente por J. González-García), que se refiere a una actitud soberbia, donde el maestro o el alumno cree saberlo todo y se posiciona por encima del paciente y de sus compañeros o colegas, con una actitud "endiosada". Dado que es difícil de autodiagnosticar, podría entorpecer en forma importante el proceso de enseñanza o fomentarlo como método de práctica profesional. Es importante en el acto médico mantener la humildad, respetar las opiniones y labores de todos los involucrados en el proceso. Esto contribuye a crear empatía con el que sufre y sus familiares para lograr el objetivo fundamental inherente en medicina que es tratar al paciente con compasión y como centro de nuestra atención. Ese es el valor esencial que se debe transmitir entre generaciones. Otra amenaza a la docencia de posgrado es la desaparición del rol de ASOFAMECH (asociación de facultades de medicina de Chile) como entidad que autorizaba la creación de programas de formación. Previamente se debía cumplir con una serie de exigentes requisitos que incluían recursos docentes, infraestructura, sistemas de evaluación, retroalimentación, uso de recursos de bienestar desde posgrado de la Universidad vinculada, entre otros, que hacía más probable una enseñanza adecuada y uniforme. Actualmente, cualquier centro puede iniciar un programa 
de formación sin necesariamente cumplir dichas regulaciones o el fin último que debiera ser la enseñanza de la especialidad. Adicionalmente, recientemente se quitó el respaldo a ÁPICE, agencia que acreditaba programas de especialidad, y que velaba porque el programa ya en curso cumpliera con normas mínimas. Ahora, la responsabilidad de acreditación recae en entidades gubernamentales que en la práctica no alcanzan a fiscalizar programas de especialidad en medicina, quedando a criterio de cada centro formador la calidad y evaluación de su propio programa. En la Sociedad de Neurocirugía estamos convencidos que la educación continua es un pilar fundamental y un deber, por lo cual desde el año 2006 se ha diseñado un reglamento de educación con reuniones periódicas. Actualmente, cuenta con 8 módulos que incorporan los conocimientos y competencias básicas de todas las subespecialidades. Está en continua evolución y pronto contará además con una parte práctica con sesiones en laboratorios de disección cadavérica. Tiene evaluación escrita y retroalimentación con comunicación directa con los jefes de programa de cada centro. Impresiona ser un aporte a la formación de residentes y a la vez está diseñada como actualización para neurocirujanos ya formados, en contexto de la recertificación médica que regirá en un futuro próximo.

Por todo lo anterior, en el presente nos enfrentamos a múltiples desafíos que se pueden enfrentar profesionalizando la educación. Creo relevante que los neurocirujanos se familiaricen con técnicas docentes y se sensibilicen con valores significativos a transmitir, realizando diplomados o magísteres en educación. Dicha instrucción nos da las herramientas técnicas necesarias, para que junto a la convicción de heredar una atención compasiva y centrada en el paciente, logremos la labor final que es enseñar bien y que nuestros alumnos aprovechen e idealmente disfruten el proceso.

Francisco Mery Jefe de Programa Neurocirugía, Pontificia Universidad Católica de Chile Secretario general, Sociedad de Neurocirugía de Chile 